\title{
Inquest Procedure: Medical Officers' Point of View
}

\author{
Ravindra Samaranayake* $\triangle($ iD \\ Department of Forensic Medicine and Toxicology, Faculty of Medicine, Colombo, Sri Lanka.
}

\begin{abstract}
When an average medical student or a postgraduate student is questioned as to why a medical officer must request an inquest for certain type of death, for example, a sudden death, the most likely answer is that 'a sudden death is included in section 370 of the CPC among the deaths for which an inquest should be held and therefore an inquest must be ordered". However, the above most common answer is not factually accurate from the medical officer's point of view. Section 370(1) of the CPC is essentially meant for inquirers and not to be regarded as instructions given for medical officers pertaining to deaths for which an inquest should be requested. Death investigation system of Sri Lanka does not place a medical officer in a special position as an informant. A medical officer carries the same responsibility as an ordinary person. The responsibility of an ordinary person regarding certain types of death is stipulated in section 21 (b) of the CPC. This fact may be of crucial importance in a case where a medical officer's decision to request or not to request an inquest for a certain type of death is questioned. However, there is no punitive action described for noncompliance of section 21(b) in CPC.
\end{abstract}

Keywords: Inquest, Medical Officer, Maternal death, Criminal Procedure Code

Copyright: @ 2017 with the Medico-legal Journal of Sri Lanka.

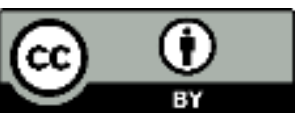

This is an open access article distributed under the terms of the Creative Commons Attribution License, CC BY 4.0 which permits unrestricted use, distribution and reproduction in any medium, provided the original author and source are credited.

Funding: None

\section{Competing interests: None}

Received: 14 December 2017

Accepted revised version: 20 March 2018 Published: 01 April 2018

https://orcid.org/0000-0002-1803-9224

*Corresponding author: Samaranayake R, Department of Forensic Medicine and Toxicology, Faculty of Medicine, Colombo, Sri Lanka. Tel: +94718037908, E mail address: ravin6260@yahoo.com

Cite this article as: Samaranayake R. Inquest Procedure: Medical Officers' Point of View. Medico-Legal Journal of Sri Lanka, 2017;5(2):1-4

DOI: http://doi.org/10.4038/mljsl.v5i2.7356 


\section{Introduction}

Teaching on inquest procedure to medical students siting the sections in the Criminal Procedure Code (CPC) which is meant to inquirers may cause confusion if the role of the medical officer in this procedure is not highlighted correctly. This paper looks into the inquest law in Sri Lanka from the perspective of a medical officer and few issues related to it.

\section{Objectives}

Implications of conventional teaching on the inquest procedure to medical officers citing sections pertaining to the inquest in the CPC.

\section{Discussion: A question and an answer}

Why certain type of deaths need an inquest is conventionally taught to medical undergraduates and postgraduate trainees in legal medicine citing the section 370 of the Criminal Procedure Code (CPC) (Act no 15 of 1979). ${ }^{[1]}$ As a result, when a medical student or a postgraduate student is questioned as to why a medical officer must request an inquest for certain type of death, for example, a sudden death, most likely answer is that 'a sudden death is included among the deaths for which an inquest should be held in section 370 of the CPC.

However, the above most common answer is not factually accurate from the medical officer's point of view. Section 370 (1) of the CPC states "Every inquirer on receiving information that a person ---”.

Hence section 370 is essentially meant for inquirers and not to be regarded as instructions given for medical officers pertaining to deaths for which an inquest should be requested.

Death investigation system of Sri Lanka does not place a medical officer in a special position as an informant. A medical officer carries the same responsibility as an ordinary person. The responsibility of an ordinary person with regard to certain types of death is stipulated in section 21 (b) of the CPC where it states, "Every person aware (b) Of any sudden or unnatural death or death by violence or of any death under suspicious circumstances, or of the body of any person being found dead without it being known how such person came by death, Shall in the absence of reasonable excuse- the burden of proving which shall lie upon the person so aware-forthwith give information to the nearest Magistrate's court or to the officer in charge of the nearest police station or to the peace officer or to the Grama Seva Niladhari of the nearest village of such sudden unnatural or violent death or death under suspicious circumstances or of the finding such dead body.

All deaths that are generally thought as an inquest is a necessity, can be accommodated in categories that are mentioned in section 21 (b) of the CPC. Hence the answer why a medical officer shall request for an inquest for certain types of death lies in section 21 and NOT in section 370 of the CPC.

\section{Is it an offence not to request an inquest?}

What if a medical officer does not request an inquest for a death which falls into section 21 (b) of the CPC. Has he committed an offence? Section 21 of the CPC does not mention of any penalty in an event of noncompliance to that section.

In some other sections of the CPC, the penalty for the violation of that section is given within the same section. Eg: Section 370 (7) of the CPC states, "Every person who so fails to attend or who refuses to take the oath of a witness or refuses any question which shall be legally asked of him, or fails or refuses to produces any document or other things shall be guilty of an offence, and shall be liable on conviction thereof to a fine not exceeding one hundred rupees, or to imprisonment of either description for any period not exceeding three months or to both".

Therefore, it is logical to assume that violation of section 21 of the CPC does not carry a punitive action. The other pertinent law with regard to the above issue is in section 174 of the penal code where it states, ${ }^{[2]}$ "Whoever, being legally bound to give any notice or to furnish information on any subject to any public servant, as such, intentionally omits to give such notice or to furnish such information in the manner and at time required by law, shall be punished with simple imprisonment for a term which may extend to one month or with fine which may extend to fifty rupees or with both".

The above section again raises the question as to whether a medical officer is legally bound to inform certain types of deaths and essentially comes back to square one.

\section{Mandatory postmortem - Is this legal under the prevailing law?}

The circular 3/2008, issued on 2008.10.02 by the secretary of the ministry of justice instructs all inquirers into sudden death to refer all, 
1. Maternal deaths

2. Deaths due to accidents

3. Deaths due to suicides

4. Deaths due to shootings

5. Deaths in which cause of death is not known to a post mortem examination. ${ }^{[3]}$

This mandatory postmortem referral is not stipulated in the CPC, and the inquirer of an inquest had the sole desecration whether to request or not to request a postmortem examination. All though, apart from maternal death, all other categories are already included in the list of deaths in which an inquest is warranted, the above circular has, in my opinion, questionable legality as,

1. Section 369 of the CPC which deals with the inquests of death is written in a negative sense where it states, "An inquest of death shall not be held except under the provisions of this code". As a result, an inquest must be held only for deaths that are mentioned in section 370 of the CPC.

2. Section 458 (1) states "The Minister may make regulations in respect of matters for which regulations are authorised by this Code to be made". Also, section (2) states "Every regulation made by the Minister under subsection (1) shall be published in the Gazette and shall come in to force on the date of such publication...." It is apparent that the CPC only empowers the minister (not the secretary) to make regulations and such regulation must be issued as a Gazette notification. Further, that particular section of the CPC should give authority for future regulations. However, chapter xxx of the CPC which governs the inquest procedure does not have a section authorising regulations.

\section{Who CAN / MUST do what?}

It is clear from the CPC that section 370 (1), where it states that deaths due to (i) suicide,(ii) animal attack (iii) machinery (iv) sudden deaths (v) an unknown cause are to be subjected to an inquest, is meant for inquirers in sudden death (ISD). Similarly section 370 (4) gives authority to magistrates to conduct inquiries of any death stated in 370 (1) if those are directly reported to a magistrate.

However, it is important to note that, as per section 371 (1) inquests of deaths occurred in the custody of the police or in a mental or leprosy hospital or prison are to be carried out only by a magistrate. This implies that all other deaths (including suspicious deaths) in which an inquest is required, both ISDs and magistrates are equally capable of doing the inquest. In other words, in the context of inquest procedure, CPC gives special recognition only in custodial deaths.

Section $370(2)$ instructs ISDs to submit reports on inquests they conducted to respective magistrates and section 9 (b) (iii) gives necessary powers to magistrates to become the 'end point' inquirer with regard to the cause of death in types of deaths stipulated in sections 370 (1) and 371 (1).

If a magistrate can mount a reasonable suspicion either from the inquest reports that are sent to him by ISDs or from the information that he has, when magistrate himself is the initial inquirer, he shall initiate the proceedings described under chapter xiv and $\mathrm{xv}$.

The supreme court judgement in the case of G.A.D Senaviratne vs. AG highlights few important aspects of the inquest procedure. ${ }^{[4]}$ Although that case dealt with the older version of the CPC and the numbering of the relevant sections is different, almost all the wording is same as the amended newer version. In the above case, Justice Tennakoon pointed out, that,

1. Legislature recognised the value of conducting inquests in custodial deaths by responsible and experienced individuals, therefore, assign those only to magistrates.

2. Functions of a magistrate or inquirer holding an inquest of deaths are of a non-judicial character.

3. Function of an inquirer or magistrate under Chapter 32 (30 in amended CPC) is to hold an inquiry into the cause of death and to state as a finding what in his opinion was the cause of death. The recording of the finding concludes the inquest of death.

4. There is no power in an Inquirer or Magistrate to pronounce any 'verdict'; his duty is only to record a finding of the cause of death; the finding by itself does not automatically initiate any legal proceedings.

\section{Conclusion}

Conventional teaching on the inquest procedure to medical officers citing sections pertaining to the inquest in the CPC where it is meant for inquirers can sometimes cause confusion and misinterpretation of facts. A correct understanding of the inquest law and duties of the medical officer in that law will place a medical officer in a better position when discharging medico-legal duties. 


\section{References}

1. Parliament of the Democratic Socialist Republic of Sri Lanka. Code of criminal procedure act, No. 15 of 1979. Department of Government Press. 1979. p 145

2. Parliament of the Democratic Socialist Republic of Sri Lanka. The Penal code. Department of Government Press. 1970. p. 332

3. Ministry of Justice. Circular No 3/2008of 02.10.2008

4. 092 New Law Report V-71. Available from: https://www.lawnet.gov. lk/1977 /12/31/g-a-d-seneviratne-petitioner-and-the-attorney-general-and-2-others respo/ 